\title{
Cartography. A book and a MOOC
}

\author{
Kenneth Field ${ }^{\mathrm{a}, *}$ \\ a EsriInc,kfield@esri.com \\ * Corresponding author
}

Keywords: education, cartography book, MOOC

\begin{abstract}
:
Cartographic education is seemingly in limbo. Courses are closing, professionally trained cartographers are dwindling in numbers and mapping is often not much more than a self-service activity. And all this against a backdrop of the massive increase in map use, the democratization of mapping and a plethora of online materials to aid the novice map-maker. We see many more maps and there's no doubt that amongst the few gems we see many more very poorly designed maps. But what of the expertise? And what of core competencies in cartography? In a world that now uses Google and Wikipedia as the go-to sage, what of the cartographic textbook? And what of core training? In this presentation I assert that the death of cartographic expertise needs to be staunched. I'll discuss two new mechanisms to approach the problem. First, a new book designed to re-imagine the dissemination of cartographic knowledge; a cartographic text book with a difference. Secondly, a Massive Open Online Course that, to date, has been taught to over 80,000 registrants worldwide.
\end{abstract}

In planning the book, over a number of years, it became obvious that there was a massive unmet need for a new book about thinking about cartography. A book that veers markedly from a traditional textbook yet delivers core concepts and cartographic principles in a new and engaging way. A book whose content is not tied to chapters but is immediately accessible through a unique structure and which keeps the often mystical cartographic vocabulary to a minimum. A book that supports new map-makers in a visually compelling way yet is mature enough to support practiced cartographers as a go-to companion. "Cartography." is that book. Published in July 2018, this major new publication is designed to engage with a modern audience keen to learn how to make better maps (Figure 1). In this presentation I will explore the need for a new book and demonstrate the void that it fills in cartographic education. I'll explain its structure as one that mirrors the map-making process - which is never one that linearly considers projections, colour, typography and so on - but one which supports the interplay of the many simultaneous decisions made in the map-making process. I'll go into detail about the book's design, format and content and link it clearly to modern praxis and learning environments.

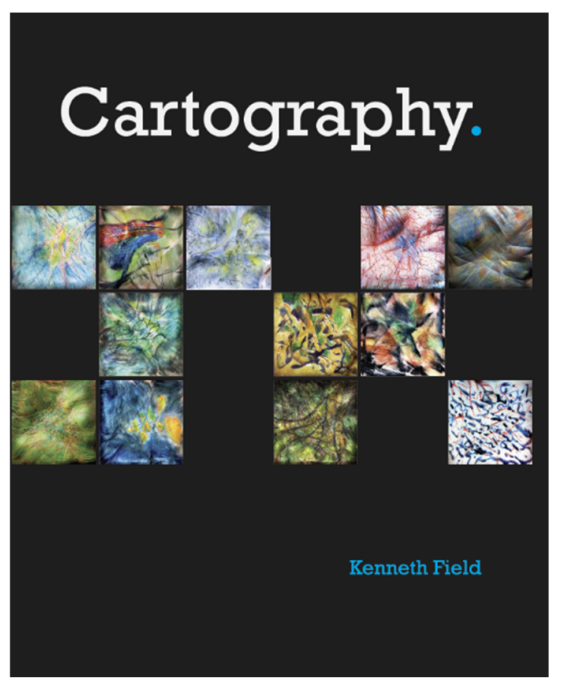

Figure 1. Cartography. by Kenneth Field

Running at 550 pages with contributions from over 20 acknowledged cartographic experts and over 300 maps and illustrations, it is bold in scope and the intent is to make this a one-stop-shop for cartography, delivering the essentials in a way that makes sense to those who have never studied cartography but which will enable them to take advantage of the many ideas and approaches that define the discipline of cartography; and for those experienced cartographers that seek a companion in their everyday work. I will explain how the book differs from what has gone before and how it supports cartographic education and practice going forward. 
Turning attention to other learning realms, I will also discuss the book's companion, a Massive Open Online Course (MOOC). To date the course has run three times to over 80,000 people. It's free and spans a 6 week period during which time students get access to videos, software, data and exercises, quizzes and access to cartographic experts via a discussion forum. Each week requires around 3-4hrs of work per week. The idea is simply to expose people to some fundamental cartographic ideas as an antidote to the simple notion that 'anyone can make a map'. While that is true, the ability to think about the map and better understand how to make decisions to make the map better are crucial. While not the first MOOC or online course in cartography, this was developed to be a bit larger in scope than those that have gone before. Figure 2 also demonstrates the international reach of the global classroom and how it has captured the imagination.

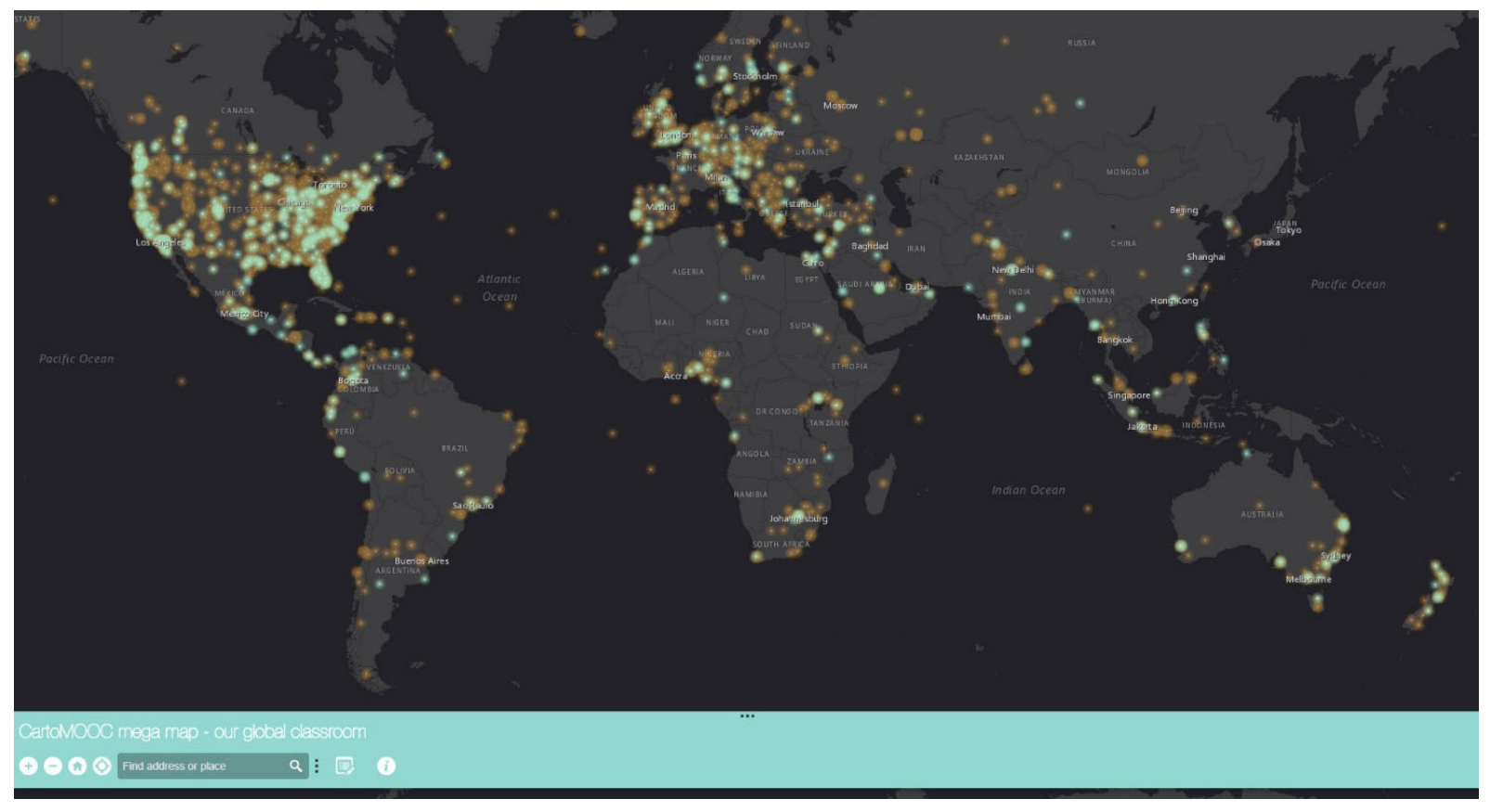

Figure 2. The global classroom of the Cartography MOOC

It's important to note that this is not a talk designed to sell anything other than the idea that we need to rethink cartographic education going forward and for cartographers to reassert their relevance as key players. The two initiatives I present her are one attempt at contributing to repositioning cartographic expertise. Going beyond the cartographic field into data visualisation, visual journalism and democratised mapping is crucial to ensure that people make maps of worth. To do that, we, as a cartographic community must find new and engaging ways, beyond our traditional approaches, to help them see that our ideas resonate and we can add value to their work. 